\title{
Commentary: Timing (and size) is everything?
}

\author{
S. Adil Husain, MD
}

\footnotetext{
From the Departments of Surgery, Pediatrics, and Section of Pediatric Cardiothoracic Surgery, University of Utah Health, Salt Lake City, Utah; and Primary Children's Hospital Heart Center, Salt Lake City, Utah.

Disclosures: Author has nothing to disclose with regard to commercial support.

Received for publication Jan 13, 2019; accepted for publication Jan 14, 2019; available ahead of print Feb 26, 2019.

Address for reprints: S. Adil Husain, MD, Departments of Surgery and Pediatrics, Pediatric Cardiothoracic Surgery, University of Utah Health, Primary Children's Hospital Heart Center, 100 N Mario Capecchi Dr, Suite 2200, Salt Lake City, UT 84113 (E-mail: adil.husain@hsc.utah.edu).

J Thorac Cardiovasc Surg 2019;157:2404-5

$0022-5223 / \$ 36.00$

Copyright (c) 2019 by The American Association for Thoracic Surgery

https://doi.org/10.1016/j.jtcvs.2019.01.055
}

Truncus arteriosus (TA) accounts for $1 \%$ to $4 \%$ of all cases of congenital heart disease. ${ }^{1}$ McGoon and colleagues ${ }^{2}$ reported on the first repair of TA with a valved homograft in 1967. Since then, improvements in cardiopulmonary bypass, surgical techniques, and postoperative management have all reduced early mortality.

In this issue of the Journal, Mastropietro and colleagues ${ }^{4}$ report the results of their multicenter analysis to identify modifiable risk factors that affect contemporary outcomes for TA. Fifteen centers contributed a cohort of 216 patients who underwent surgical intervention from 2009 to 2016. Mastropietro and colleagues ${ }^{41}$ report an incidence of major adverse cardiac events (MACE) of 20\%. MACE consisted of postoperative death or need for extracorporeal membrane oxygenation or cardiopulmonary resuscitation. Failure to diagnose TA before discharge from the nursery, cardiopulmonary bypass time longer than 150 minutes, and use of a valved conduit larger than $50 \mathrm{~mm} / \mathrm{m}^{2}$ indexed to body surface area were independently associated with MACE.

The cohort represents on average less than 2 patients per institution per year. Identifying reproducible approaches to care when incidence of intervention is low can create inherent challenges. The study cohort is not derived from a national registry, but rather from 15 institutions whose inclusion was the product of professional associations with each other. The article excluded program size, case mix, or geography as variables for program participation. This is to not impute lesser significance to the findings, but rather to outline the potential lack of random sample analysis. Indeed, Mastropietro and colleagues ${ }^{4}$ are to be commended on an exhaustive process requiring detailed communication and collaboration.

Identification of failure to diagnose TA before discharge from the nursery as a risk factor raises several inherent questions. This variable was not associated with mortality alone. The need for extracorporeal membrane oxygenation or cardiopulmonary resuscitation, however, may be associated with neurologic outcomes that have a great effect on

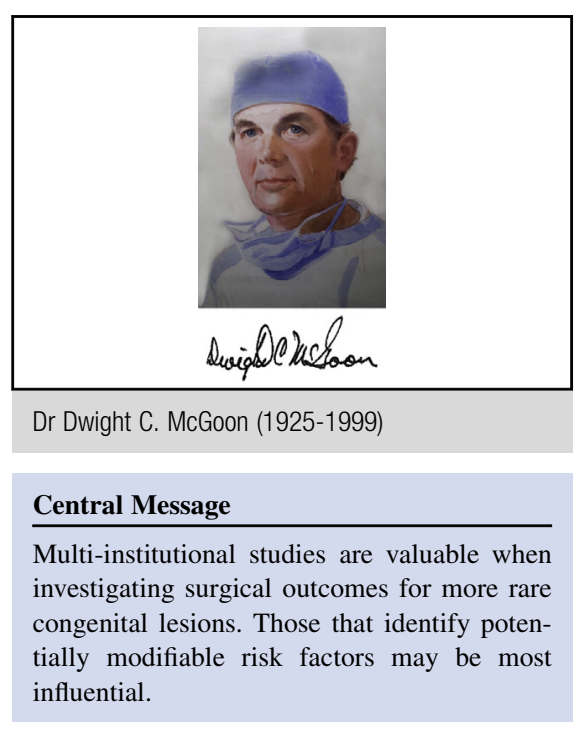

See Article page 2386.

survivors. This association is consistent with value in neonatal screening protocols and the belief that neonates with TA should undergo surgical correction before discharge. $^{5}$

A cardiopulmonary bypass time longer than 150 minutes and its association with higher incidence of MACE and higher mortality in TA is described. Mastropietro and colleagues ${ }^{4}$ performed an additional sensitivity analysis in which they excluded 37 patients who required concomitant truncal valve intervention; this still revealed an independent association with MACE. This exact time point cannot be viewed as a profound inflection point of effect on surgical precision and judgment, but it also cannot be ignored as an authentic statistical finding within the study.

That larger conduits were associated with a higher incidence of MACE was arguably the most surprising association. Previous studies describe larger conduits as being associated with longer freedom from reintervention. ${ }^{6}$ Perhaps this belief should be reexamined for patients with specific anatomic substrates. Mastropietro and colleagues ${ }^{4}$ were purposefully nondescriptive regarding the potential technical and physiologic reasons for this association, but its deviation from previous data is worthy of recognition.

An evolution of outcomes publications that involve multi-institutional collaborations continues to be valuable to our sub specialty. This is especially important when analyzing rare lesions. Collaborative studies that focus on modifiable risk factors for programmatic strategies of care 
and surgical technical variables are perhaps the most insightful and potentially transformational.

\section{References}

1. Collett RW, Edwards JE. Persistent truncus arteriosus: a classification according to anatomic types. Surg Clin North Am. 1949;29:1245-70.

2. McGoon DC, Rastelli GC, Ongley PA. An operation for correction of truncus arteriosus. JAMA. 1968;205:59-73.

3. Pearl JM, Laks H, Drinkwater DC Jr, Milgalter E, Orrin-Ailloni-Charas, Giacobetti F, et al. Repair of truncus arteriosus in infancy. Ann Thorac Surg. 1991;52:780-6.
4. Mastropietro CW, Amula V, Sassalos P, Buckley JR, Smerling AJ, Iliopoulos I, et al. Characteristics and operative outcomes for children undergoing repair of truncus arteriosus: a contemporary multicenter analysis. J Thorac Cardiovasc Surg. 2019;157:2386-98.e4.

5. Hanley FL, Heinemann MD, Jonas RA, Mayer JE Jr, Cook NR, Wessel DL, et al Repair of truncus arteriosus in the neonate. J Thorac Cardiovasc Surg. 1993;105: 1047-56.

6. Poynter JA, Eghtesady P, McCrindle BW, Walters HL III, Kirshbom PM Blackstone EH, et al. Congenital Heart Surgeons' Society. Association of pulmonary conduit type and size with durability in infants and young children. Ann Thorac Surg. 2013;96:1695-701; discussion 1701-2. 